\title{
Globalization and Transnational Advance Fee Fraud: A Study of Perceptions of Undergraduates in Southeastern Nigeria
}

\author{
Ngozi G. Egbue \\ Department of Sociology/Anthropology \\ Nnamdi Azikiwe University, Awka
}

DOI: $10.36108 / \mathrm{NJSA} / 9002 / 70(0140)$

Vol. 7 Issue 1, 2009

\begin{abstract}
Transnational advance fee fraud has become a public issue since the 1980s, and has grown world wide within a background of corrupt dealings in foreign exchange and the transfer of illegally obtained money through foreign businesses and enterprises. In the Nigerian context, the general economic impoverishment with the attendant desperation of the educated to create self-employment and generate wealth, together with a tendency to get-rich-quick, constitute the background within which advance fee fraud has grown. At the global level, while contacts between different parts of the world have grown tremendously, with increasing potentials for personal, business and other forms of exchange, yet racial identities quite evidently tend to remain resilient, resulting in various forms of divisions and conflicts. This paper sought, with the use of a questionnaire, focus group discussions and interviews to examine the perception of undergraduates in southeastern Nigeria about certain aspects of this scam. This is because these youth are considered to be most predisposed, by virtue of their education, constant access to the internet, unsatisfied financial needs and the threat of imminent unemployment, to temptations to engage in advance fee fraud. The findings indicated that undergraduates were very familiar with advance fee fraud as a major economic activity. Furthermore, it was found that undergraduates generally viewed internet scam as less grievous than other irregular sources of income, largely because the victims were mainly foreigners, and also because there was usually no direct contact with victims. The study made recommendations for improved enlightenment of youth, stricter overall anti-corruption law enforcement, and increased employment opportunities for undergraduates.
\end{abstract}

Key words: globalization, advance fee fraud, youth, corruption, racism

\section{Introduction}

Economic crimes in general are on the increase throughout the world in spite of the efforts over the years by both general and specialist law enforcement agencies and organizations to curtail them. Advance fee fraud constitutes a major dimension of economic crime, and has in the past decades posed serious threat to international business enterprise (Peel, 2006). This form of fraud is relatively new especially in Africa when compared to other types of economic crimes. Before the 1980s economic crimes were predominantly in the form of sharp practices by government functionaries and agents responsible for handling tax payments and other official monies. They include financial misappropriation, fraud, false pretences in aid of fraudulent activities, counterfeiting, forgery and assurance of false prospects (Asiama-Sampong, 
2005). Such crimes required the offender to be in custody of or to be a trustee of property or resources. Over the years these crimes have become closely tied to globalization especially in connection with advancement in communication and other forms of advanced technology, as well as advancement in financial markets, credit financing and expansion in scope of international trade. Thus, those who are minded to commit financial crimes now have additional opportunities and modes of operations that include telephones, fax and computer/Internet. With these advanced information technologies, the activities of perpetrators of financial crimes have over time permeated and are threatening to strangulate entire economies.

The Nigerian variant of advance fee fraud is popularly known as "419 fraud". This name is derived from a formerly relevant section of The Criminal Code of Nigeria. The term "419" usually denotes a sub-classification of advance fee fraud crime in which the perpetrators are primarily Nigerians operating globally, whether in Nigeria or elsewhere. Logan (2006) noted that 419 operators have spread throughout the globe, with a particular large base in Europe. According to Peel (2006) this Nigerian-dominated form of fraud is a source of huge losses to people world wide; and in Britain in particular, to the tune of hundreds of millions of pound sterling annually. Statistics presented at the International Conference on Advance Fee Fraud (419) in New York on September 17, 2002 quoted by Vaknin (2005) show that annual losses to the 419 scam in the United States amounted to more than $\$ 100$ million, while global losses stand at over $\$ 1.5$ billion. It was also noted by this source that Nigerian letter fraud constituted about 15.5 percent of all such crimes worldwide. Basically, the scam is operated by sending unsolicited mail proposing a business deal of an illegal or even ostensibly legal or legitimate nature. A common feature of this form of fraud is that victims are requested to pay something in advance or upfront. Despite being clearly proscribed by Nigerian law, the practice is both rampant and surprisingly open in many Nigerian urban centers, especially those with large population of students of tertiary educational institutions and/or large stock of unemployed young graduates.

\section{The Problem}

Nigeria, as a developing nation, requires both the partnership and the sponsorship of more developed nations in order to optimize her potentials for socio-economic and political development. However, already militating against this situation is constant eruption of violence, in various parts of the country as a result of religious, political and ethnic divisions, resulting in poor security of life and property as shown by Gaye (1999). Additionally, there are several negative backlashes due to poor governmental structures and economic deprivation of the masses. These give rise to mistrust, fear by business entrepreneurs and increasing desperation on the part of Nigerian youth. Advance fee fraud extends this situation of internal insecurity of which the global community is already largely conscious, by further directly threatening Nigeria's short-term business connections with Western entrepreneurs. The 
latter are often driven by the hope to make quick sizeable profits without the risk of setting up any infrastructures or even visiting the country.

Advance fee fraud therefore, poses a strong threat to Nigerian economy as it tarnishes the country's international image. Furthermore, it discourages foreign investment by making upright foreign investors fearful, to the extent that they tend to see every Nigerian business proposal as illegal or fraudulent (Gbadebo, 2009; Bloch, 2007). This kind of image would continue to jeopardize Nigerians economic relations, if drastic measures are not taken to bring about urgent change.

A substantial number of undergraduate participation in the 419 scam (Freeman Institute, 2000; Mbachu, 2005; Trevelyan, 2009) is explicable by the presence of the following factors. One is that they are increasingly required to have computer literacy as part of their academic programmes. Secondly, due to the increasing availability of internet access and its uses for general enlightenment and academic enquiries, undergraduate are expected to be more conversant with this source of information than their less educated counterparts. Consequently, more than an estimated 60 percent of those found in cyber cafes in towns with tertiary educational institutions are undergraduates. Thirdly, due to general impoverishment of the Nigerian population, and in particular unemployment of graduates, and unavailability of bursaries and scholarships, youth in higher educational institutions are often hard pressed to obtain necessary funds during their education.

Foreign victims of the 419 scam come from all walks of life. There are housewives, politicians and lawyers, as shown in http://arstechnica.com/old/ content/2006/077307.ars, and by Anderson, (2006). Victims also include astute business persons such as bankers (Adebayo, 2001) and merchants (Bloch, 2007). Most foreign victims, who have hired investigators to come to Nigeria, or have personally travelled to Nigeria in quest of their illegal or fictitious business partners, often have little or no success in retrieving the fund they have lost to scammers. There are even instances of a few foreign victims who, being unable to cope with their losses, have committed suicide, while some others became addicted to drugs or turned into full blown criminals as a result of their traumatic experiences (Harnaford, 2007).

Not surprisingly globalization has tended to bring this crime to the doorsteps of the inhabitants of the global village as shown by Barlow (2001) and United Nations (2005). This global scope clearly underscores the extent of its damage to the development of international trade and market, in addition to the acute constraint it poses to Nigeria's internal economic order, and international economic and political relations.

\section{Research Objectives}

The overall objective of the study is to identify the views of undergraduate students about the relationships between the 419 scam, themselves, and certain national and global factors. The specific objectives include: 
- To establish the perceptions of undergraduate students on the extent of their participation in the 419 scam.

- To identify the perceptions the students on global and national factors that foster the 419 scam.

- To establish undergraduates' views about the impact of the 419 scam on Nigeria's international image.

- To obtain the views of the undergraduates on how to curb the 419 scam.

\section{Significance of Study}

An examination of the 419 scam for the purpose of establishing its relationships with certain socio-economic and political factors at national and international levels has important practical and theoretical significance. First, the study has practical value as a source of clearly articulated views of undergraduates; as those who possess high potential for immediate and later perpetration of the 419 scam. This is because 419 related perceptions by youth in this subgroup is crucial to the success of any comprehensive strategy for curbing 419 scam, that has been globally identified as posing severe constraint to Nigeria's socio-economic development. On the other hand, as a forerunner into research dealing with any particular sector of 419 scam perpetrators, this study also possess immense theoretical significance. This is because by throwing light into undergraduate 419 scam activities, it provides valuable insight into the relationships that culminate in pulling this sector of youth into what constitutes a major gestation process; for continuation and consolidation of the 419 scam.

It should be noted that few scholars have carried out studies on the 419 scam in general. Notable exceptions are Apter, 1999; Smith, 1999 and Reich, 2004. However, none of these has been identified in the particular area of this study. Furthermore, sociology has paid little attention to the general area covered by corruption and related deviance, as observed by Hanker (2006). This work is therefore meant to serve as an exploratory survey, which by highlighting the undergraduate dimension of the 419 scam, would elicit more in-depth studies into this area.

\section{Theoretical Framework}

The study subscribes generally to the functionalist view that the source of deviance is located within the very structure of society. An example of this is the view posited by Cohen (1955). He argued that youth in the lower working class, who are frustrated with their positions in life, often band together in delinquent subcultures that reject middle class mainstream values and replace them with norms that celebrate non-conformity and defiance. In Nigeria there are some elements of interaction between youth subculture and deviance, despite the fact that class structure is generally less rigidly defined than in the western world.

Another related theoretical viewpoint is that of the New Criminology theories. The views of Conflict Criminologists such as Taylor, Walter and 
Young (1973) have strong bearing on the issues involved in the 419 scam. These sociologists argued that individuals actively choose to engage in deviant behaviour or even crimes as a response to inequalities inherent in the capitalist system. In line with this view, other conflict criminologists have also posited views, that maintain that the criminal justice system or the creation of laws actually favour the interests of the wealthy against those of the working class. They also argued that the powerful elements in society break laws but are rarely caught. Fearful of the consequences to their own interests if they pursue much more significant white collar crimes committed by the rich and powerful, law enforcement officers prefer to pursue less powerful members of the society, according to Pearce (1976) and Chambliss (1978). Spitzer (1980) another conflict theorist has argued that those in the higher socio-economic strata of society tend to apply criminal labels on those who in any way challenge the capital system, with intent to discredit the legitimacy of their challenge. Furthermore, Igbo (1999) argued that capitalist economies tend to widen the gap between the rich and the poor. Consequently the poor often resort to stealing from the rich as a means of survival.

While most of these theoretical views focus on deviance and criminality within national units, they could be usefully extended to cover inequalities at the global stratification level. In this way, the 419 Scam and the furore that it presently generates could represent a classic example of labelling of the powerless in society with stigmas that big business operators may have long deserved. This is because despite the much vaunted fine business ethics to which developed countries' business entrepreneurs lay claim, the reality is sometimes the reverse, especially in their relations with developing countries. Indeed transnational 419 scam could be viewed, albeit satirically, as representing an attempt by some citizens of developing countries to minutely adjust very disadvantageous global market structures, in order to facilitate their own designs for economic survival.

Another important issue here is the use of goods produced by developed economies for purposes not intended by the producers. McGrew (1992) observed that sociologists usually view globalization as a process whereby societies, communities and individuals are increasingly interconnected around the world. Through globalization social processes in one part of the world usually impact on those in other parts. Cultural implications of globalization have been of particular interest. Globalization is quite often portrayed as a process in which the individual is helpless. In this regard, the multi-national cultural conglomerates are viewed as relentlessly dominating popular culture across the world. The process of wiping out regional and local cultures is deemed to be in progress, and accelerating as a result of global uniformity in areas such as fast food outlets, popular soft drinks brands, advertisement, fashions, satellite television shows, and popular music.

The size and dominance of these conglomerates often place them in positions of considerable control over modalities for development of cultural markets and the marketing of products. Furthermore, the declining vitality of 
cultural institutions in the public sector, such as government television, public libraries, public antiquity projects; together with growing emphasis of many governments on privatization policies, have further strengthened their positions. Within a developing country like Nigeria the corporations exert immense control on markets, more especially through the manipulation of corrupt government at the expense of the citizenry.

However, some sociological investigations into the consumption patterns of some groups contradict above view. Fiske (1989) for instance, argued that while advertising, marketing and the media generate tremendous energy in capitalist societies geared at enhancing consumption; consumers do not always conform to the patterns anticipated by capitalism. He asserts that consumers sometimes use commodities in a subversive way. For him, a process of "excorporation", through which commodities produced by capitalism are used in ways not originally intended by consuming subordinate groups, serves as a means of opposition and cultural resistance. Fiske (1989) concluded that popular culture is often an outcome of the resistance of oppressed and subordinate groups. While Fiske's conclusion may be seen as simplistic; his demonstration that commodities may be used outside of their original purposes is generally acceptable. For instance, in the Nigerian context, use of e-mail, facsimile and other Internet connections for advance fee fraud definitely does not comply with intentions of the capitalist producers, though it does not essentially interfere with the huge profits they enjoy. To some extent this deviation from the intentions of the producers of a commodity can be likened to the use of Dr Martin boots by the British skinheads, and the take-over of Vesper motor scooters, originally intended for women riders, by 'modes'. As Golding and Murdock (1991: 30) observed; "Consumption attitudes are clearly not completely manipulated by the strategies of cultural industries, but they are equally completely not independent of them".

\section{Methodology}

The study is in the form of a perception survey. A sample of students was obtained from three universities in southeastern Nigeria located at Enugu, Awka and Abakaliki. These were purposively selected from a total population of eleven such institutions in 2007/2008. Geographical spread coupled with level of availability of internet accessing facilities were the primary criteria utilized to select the sample of tertiary educational institutions. In terms of the level of urbanity of the university location and proximity of campus to an urban centre, Enugu was the highest, followed by Awka and then Abakaliki. Availability of cyber cafes and undergraduates' use of computers for access to the internet was also highest in Enugu, followed by Awka and then Abakaliki.

Focus group discussions by undergraduates, semi-structured interview of three senior administrative personnel in each of the institutions and a questionnaire for undergraduates, were the instruments employed for data collection. Availability sampling technique was used to obtain a total of 180 focus group discussants; 60 from each institution. Discussants in each 
institution were obtained from a sample of five subgroups. This was made up of four final year students groups obtained from a random sample of four academic faculties, and one second year students group. This latter group served as source of comparison with final year undergraduates for level of awareness about the 419 internet scam. Focus group discussions were considered useful due to the fact that it facilitated uninhibited and highly informative discussions involving several undergraduates at the same time.

Interview of senior administrative officials in the educational institution served to provide background information about the institutions, undergraduate internet access and their income earning activities. A questionnaire was also utilized to obtain information from undergraduates. This was administered only at Awka, due to the limitations of time and finance, and served to augment information obtained from the focus group discussions with regard to undergraduate perception of the state of unemployment, the causes of 419 , and the threat that it poses to the nation's socio-economic well-being. A total of 120 copies of the questionnaire were administered, while 78 were returned.

Frequency distribution and percentages represented on tables were used to analyze data obtained from the questionnaire, while data obtained from the focus group discussions and interviews were analysed using qualitative, mostly descriptive, method.

\section{Findings}

\section{Students' Perception of Global and National Structural Factors that Foster} 419 Scam

Table 1 shows that $48(61.53 \%)$ of the respondents claimed that one could get a job within a period of one to six months after graduation, 17 (21.79\%) opted for the interval of seven months to one year, 10 (12.8\%) chose the interval of one to two years, while $3(3.84 \%)$ indicated two years or more. The 1-6 months duration here clearly varies from views obtained from interviews and focus group discussions. However, this may represent respondents' acknowledgement of immediate post graduation temporary employment that often represented underemployment. From this first job the new graduate, having acquired more familiarity with the employment market, seeks gradually to access improved employment opportunities. Also most of the respondents in this category would be looking more towards the sixth month, than at the earlier part of this first period.

Table 1: Students' perception on duration of getting employed after school

\begin{tabular}{|l|c|c|}
\hline Waiting Period & Frequency & \% \\
\hline 1 month - 6 months & 48 & 61.5 \\
\hline 7 months - 1years & 17 & 21.8 \\
\hline 1 year - 2 years & 10 & 12.8 \\
\hline 2 years and above & 3 & 3.9 \\
\hline Total & $\mathbf{7 8}$ & $\mathbf{1 0 0}$ \\
\hline
\end{tabular}


In terms of factors associated with the tendency for engagement in 419 by undergraduates, table 2 indicates that poor parental focus on upbringing has the highest frequency ( 22 respondents). This represents respondents' awareness of a tendency for parents to be negligent of their parental or child upbringing roles, often due to acute economic pressures. Peer group influences closely followed with 21 respondents. Next is parental inability to provide for the undergraduate's educational fees with 10 respondents.

Table 2: The most common reason why undergraduates engage in irregular economic activities

\begin{tabular}{|l|c|c|}
\hline Reason & Frequency & \% \\
\hline Poor parental focus on their upbringing role & 22 & 28.2 \\
\hline Imitation of school friends and acquaintances & 21 & 26.9 \\
\hline Pressure of out-of-school friends & 5 & 6.4 \\
\hline $\begin{array}{l}\text { Pressure to obtain extra money to satisfy } \\
\text { unanticipated needs }\end{array}$ & 7 & 9.0 \\
\hline Parents' inability to pay school fees & 4 & 5.1 \\
\hline $\begin{array}{l}\text { Undergraduates' resentment against increase in } \\
\text { school fees }\end{array}$ & 10 & 12.8 \\
\hline $\begin{array}{l}\text { Undergraduates' tendencies to live above their } \\
\text { means }\end{array}$ & 2 & 2.6 \\
\hline Other factors within educational institutions & 2 & 6.4 \\
\hline Other factors beyond the educational institutions & $\mathbf{7 8}$ & $\mathbf{1 0 0}$ \\
\hline Total
\end{tabular}

With regard to above issue, undergraduate focus groups discussants generally saw globalization as a positive force, because it contributed to advancement in cultural, economic, political and technological dimensions of life. They also expressed the view that by opening up global trade, employment markets and other forms of opportunities for economic activities and exchange, globalization has tended generally to improve life chances. They acknowledged opportunities provided particularly by computer technology and internet for enhancing educational and employment opportunities for youth, among others. A few discussants, however, pointed out some existing inequalities in global trade relations. Four of the discussants in Enugu highlighted some global export trade inequalities and some weaknesses of the African Union. Expressions such as 'cheating' 'racism' and even '419' were used to describe global trade situation.

There was keen awareness that existing adverse economic situations constituted powerful constraints to youth development. In particular, fears were expressed about high rate of unemployment especially for school leavers and graduates. This situation, they claimed, rendered their education "useless", and thus contributed to the exacerbation of advance fee fraud and other crimes as means of survival. Some of the discussants blamed 'bad' and 'corrupt' governance and a general neglect of the interest of youth, as major factors pushing undergraduates and young graduates into advance fee fraud. 
Twenty eight final year undergraduate discussants in Enugu, that is fiftyeight percent of the 48 final year discussants, viewed advance fee fraud as opportunity for youth to utilize their intelligence to obtain income. Twelve (25\%) of the discussants in that group graphically demonstrated the freedom with which the politicians and other so-called business moguls manipulated the country's economy to achieve their own personal inordinate gains to the economic disadvantage of the masses in Nigeria. They also claimed that internationally directed advance fee fraud was less grievous than internally directed ones. They argued that while foreign scam victims operated legitimate businesses in their own countries, they were generally eager to undermine the economy of developing countries. In their opinion foreign scam victims did not want "clean" business, anyway. Developed nations' control of information technology was what enabled them to focus blame on Nigeria for the 419 scam.

In their opinion, the role of Nigerian youth in the 419 scam was exaggerated by foreign media; the willingness of their victims from developed countries to patronize the illegal deals was often understated. Discussants also generally viewed police activities directed against 419 as representing a case of "blaming the victim". There was a consensus that corruption by government officials was depleting the country of vast economic resources. The police was variously described as "corrupt", "bad" "dirty". All discussants decried police swoops on internet cafes as "indiscriminate", "demanding bribery", "harassing" and part of a general pattern of "victimizing youth". Furthermore some discussants wondered why the police do not prevent government big shots from carting away huge sums of Nigerian wealth to foreign banks. Unemployment, lack of bursaries, and government unresponsiveness to the general needs of the populace were cited as encouraging the 419 scam.

\section{Undergraduates' Perception of the Extent of their Participation in 419 Scam}

In table 3, it is observed that advance fee fraud was seen by respondents as less common than commercial sex and armed robbery. However, almost twenty percent of the respondents considered it to be the most common undergraduate irregular economic activity. This indicates that 419 scam is substantial among undergraduates.

Table 3: The most common recent irregular economic activity by undergraduates

\begin{tabular}{|l|c|c|}
\hline Activities & Frequency & \% \\
\hline Commercial sex & 37 & 47.5 \\
\hline Robbery & 20 & 25.6 \\
\hline Advance fee fraud & 15 & 19.2 \\
\hline Non response & 6 & 7.7 \\
\hline Total & $\mathbf{7 8}$ & $\mathbf{1 0 0}$ \\
\hline
\end{tabular}

Table 4 indicates that 3.8 percent of the respondents thought that over 80 percent of undergraduates were involved in the 419 scam. About 13 percent of 
the 65 respondents who indicated their choice and 10.3 percent of total respondents were of the view that 41-60 percent of undergraduates were involved in 419 activities. Nearly 21 percent of respondents were of the view that over 41 percent of undergraduates engage in 419 activities.

Table 4: Percent of undergraduates perceived to be engaged in different irregular economic activities

\begin{tabular}{|l|c|c|c|c|c|c|}
\hline & \multicolumn{2}{|c|}{ Commercial sex } & \multicolumn{2}{c|}{ Armed robbery } & 419 scam \\
\hline \% range & Freq. & $\%$ & Freq. & \% & Freq. & \% \\
\hline $20 \%$ or less & 8 & 10.3 & 21 & 26.9 & 27 & 34.6 \\
\hline $21-40 \%$ & 27 & 34.6 & 26 & 33.4 & 22 & 28.2 \\
\hline $41-60 \%$ & 21 & 26.9 & 16 & 20.5 & 8 & 10.3 \\
\hline $61-80 \%$ & 12 & 15.4 & 4 & 5.1 & 5 & 6.4 \\
\hline $81-100 \%$ & - & - & - & - & 3 & 3.8 \\
\hline Non response & 10 & 12.8 & 11 & 14.1 & 13 & 16.7 \\
\hline Total & $\mathbf{7 8}$ & $\mathbf{1 0 0}$ & $\mathbf{7 8}$ & $\mathbf{1 0 0 \%}$ & $\mathbf{7 8}$ & $\mathbf{1 0 0 \%}$ \\
\hline
\end{tabular}

Data obtained from focus group discussions indicate that advance fee fraud was one of the safest ways by which undergraduates and young graduates could earn income. In their opinion about $50 \%$ of undergraduates engaged in advance fee fraud. They also considered it to be less hazardous for perpetrators than other anti-social economic activities such as commercial sex, armed robbery, stealing within the campus, forgery of certificates and admission racketeering. The consensus among discussants was that about $45 \%$ of female undergraduates engage in commercial sex at some point, while about $40 \%$ of males engage in armed robbery.

Some common reasons given by discussants for undergraduates' involvement in the above activities include:

1. Acute need for money for fees and other necessities for which they find no legitimate means to obtain.

2. Peer pressure on the undergraduates to conform to what is considered the norm in income earning.

3. Ease of deriving large funds from such acts.

4. Isolation from parental and other regulative family influences.

5. A get-rich-quick-by-all-means value-orientation in the society.

6. View of foreigners (from developed countries) as less grievous targets of crime.

They stated repeatedly that the 419 scam was 'easy'; and that it could take place anywhere, in cyber cafes, student hostels, at home. It was their view that one could combine studies with making money on the net. In contrast, immoral income earning activities such as commercial sex expose one to disease, abortion and the likes. In the case of armed robbery according to a discussant, "life is at stake: gunshots wounds or even death are possible," to both perpetrators and victims. Discussants describe the latter as "high risk" activity. 
At the three universities, discussants shared the view that over $30 \%$ of youths in general, and more than $40 \%$ of educated youths suffered from unemployment or acute underemployment. There was a general agreement also that up to $80 \%$ of 419 scammers were undergraduates, unemployed recent graduates or drop-outs from tertiary educational institutions.

\section{Students' Views about any Existing Racial Factors in 419 Scam}

This objective was treated at the level of focus group discussions only. Firstly, There was a general agreement that 419 scammers found it more profitable to operate at the international level and to target foreigners. There was also a consensus that since the status and worth of the dollar, pound sterling or euro were higher than the naira, there was much higher profit in targeting white victims. Additionally, however, discussants expressed strong racial sentiments, such as "whites want to dupe us", "they like to cheat us", and "they think we are fools". Examples were given of the transatlantic slave trade and the dependency relationship fostered by colonization and colonial regimes, as well as current complicity of some multinational companies with Nigerian government officials to defraud the country of huge sums.

The discussants generally claimed that continued susceptibility of westerners to advance fee fraudsters, in spite of abundant official warnings, was an indication of their deep-rooted conviction that they were intellectually superior to Nigerians and could manipulate them. Most discussants supported claims that "whites" liked to look down on and cheat "blacks". One of the discussants bitterly recounted how a Nigerian based foreign owned oil company had carried out racial discrimination against his brother by denying him due promotion. However, two of the discussant, one male and one married female did not agree that these grievances constituted sufficient excuse for the 419 scam. They insisted that "all financial crimes" were signs of "low morality and greed."

Indigenes of developed nations were said to always welcome every opportunity to defraud blacks. One student spoke at length about the Niger Delta, stating that "whites have brought environmental pollutions as price for taking all our oil. They have stolen our oil and paid us with hunger and death". "They are public enemy number 1". "They do not see us as people". Most discussants were in agreement. Thirty-six out of forty-eight discussants at Awka (75\%) agreed that up to two-thirds of undergraduate 419 scams was directed at whites. In their words, this was because "they are the rich people of the world". Thirteen of these discussants (about 28\%), however, agreed with the observation that "not only whites but every foolish and greedy person can be duped."

\section{Students' Views about the Impact of 419 on Nigeria's International Image}

Table 5 indicates that only 10.3 percent of total respondents regarded the 419 scam as being more problematic to society than commercial sex and armed robbery. In contrast 46.1 percent and 38.5 percent of respondents regarded 
armed robbery and commercial sex respectively to be the more problematic to society. The implication here is that 419 scam is regarded as less of a problem to the country's socio-economic and political development than the other antisocial activities, since $84.6 \%$ of respondents considered it to have less negative impact on society than armed robbery and commercial sex.

Table 5: The most problematic to society of the three undergraduate irregular activities

\begin{tabular}{|l|c|c|}
\hline Irregular economic activities & Frequency & Percentage \\
\hline Commercial sex & 30 & 38.5 \\
\hline Armed robbery & 36 & 46.1 \\
\hline 419-scam & 8 & 10.3 \\
\hline No response & 4 & 5.1 \\
\hline Total & $\mathbf{7 8}$ & $\mathbf{1 0 0}$ \\
\hline
\end{tabular}

Similarly, focus group discussants generally showed little concern about the impact of the 419 scam on national development or the country's image. One of them observed that "we are making money for our country. After all, it is our money, because whites stole it from us in the first place. We are bringing back this stolen money to help develop our country." Another discussant stated that "it is government corruption that is piping all Nigeria's money into foreign banks. These white countries play tricks on our corrupt government officials and then seize their ill-gotten money in the foreign banks. That is what is wasting Nigeria's money and making our country to be poor". Most of the discussants agreed with these statements. Another discussant also observed that there was lack of necessary infrastructure and services. "No electricity, bad roads, poor health-care system and so on". These, he stated to the agreement of other discussants, were larger sources of loss of foreign legitimate business than the 419 scam.

\section{Necessary Inputs into Curbing the 419 Scam}

This was dealt with by focus group discussants who clearly viewed employment creation as vital to any sizeable reduction of 419. They also pointed to the need for reduction of corruption among top politicians and other high office holders, and for good governance aimed at reducing the impoverishment of the Nigerian populace, and the youth in particular. Also implied in the statements of discussants is the need for reduction of the social distance between developed and developing nations. In spite of the connectivity engendered by globalization, youth in Nigeria perceive the marginalization that they regard as apparent in the socio-economic relations between rich and poor sectors of the world as grossly unfair.

\section{Focus groups discussions by second year undergraduates}

These groups were generally less knowledgeable about key issues involved in advance fee fraud. For example, they could not give estimates about rate of unemployment. They were also not familiar with international relations and 
implications of the 419 fraud. They were however certain that many graduates still remained unemployed or underemployed one or more years after graduation. At the three institutions, there was general agreement that over $50 \%$ of 419 scammers were undergraduates and new graduates. Discussants recounted police raids on cyber cafés, and regarded police focus on the 419 scam as excessive. They associated undergraduate 419 scamming with general poverty and unemployment, though factors such as opportunities provided by the internet, greed and gullibility of foreigners, were also mentioned as important factors. Verbal denigration of foreign victims was also common. What was deemed to be police harassment of some actually innocent students found at internet cafes was highlighted. The 419 scam was generally seen as an extension of a general environment of illegality and cheating meted out to all types of vulnerable persons.

\section{Discussion of Findings}

The root causes of 419 , according to data obtained from this study, were mainly economic, in the sense that the youth set out to engage in 419 scam in order to obtain some income. The 419 scam therefore did not originate as an organized activity against any set of individuals or groups. From the discussions, high level of unemployment and low income in Nigeria constitute a big burden on the youth in general and those graduating from tertiary educational institutions in particular. The World Bank (1996) estimated that about $66 \%$ of Nigerians at the time were living in poverty. By $2004,70 \%$ of Nigerians were living below the poverty line, in spite of substantial improvement in the Nigerian economy from its 1990s situation (Nigeria, 2004). This clearly points to some poverty creating structures within Nigeria's socio-cultural, political and economic fabric.

The fixation about foreigners' past and present offences came in handy as justification for the international dimension of this crime. Most discussants accepted and articulated this justification. Their views that the country's large scale corruption is to some extent fuelled by unscrupulous business operators and entrepreneurs from developed nations may also be related to the 419 scam as a form of retaliation.

Debt burdens that were seen as unfairly or even corruptly imposed on Nigeria was regarded as another source of the impoverishment of the country, in addition to her internally generated inadequacies (Sofo et al., 2003). The wide scale publicity given to issues of debt reduction had aspects of unfairness to Nigeria. Some discussants expressed opinions to the effect that these loans were, in the first place, corruptly obtained and disbursed with the collusion of officials and agent.

Close connections between the impoverishment of developing regions and some negative activities of Western countries is not new (Rodney, 1982; Fanon, 1983). It is also generally acknowledged that the focus on the Western pattern of development has brought about some problems of social injustice and wide gap between the rich and poor (Seabrook, 1998; Egbue, 2008). 
Unscrupulous, exploitative and corruption oriented activities of transnational companies also constitute part of the problem. Quite often these activities involve outright disregard for the well being of citizens of their local sources of wealth. This is in line with views indicated in Africa Development Report (2003).

Quite clearly racist sentiments have some place in the perpetration of the 419 scam, even if only as a salve for conscience (Vaknin, 2005). However, this is intermingled with several other factors such as need for income, nonavailability of opportunities for legitimate economic activities, and the relative safety of 419 activities. It is also necessary to observe that since Nigeria is generally known for tendency towards ethno-cultural divisions and fragmentation, sentiments of national identity on the scale identified among this sample of undergraduates, may be viewed as representing a positive force. However, its use as justification for anti-social activity remains problematic. This situation points to a need for publicizing positive aspects of international relations. References made by some of these undergraduates to 419 Scam as an alternative to suicide bombing is particularly questionable. It may however, be explained as an outcome of youth frustrations and attendant feelings of powerlessness, due to inability to effect basic improvements in their lives. It may also represent some connections (realistic or otherwise) with past and/or present Nigerian economic and political impoverishment that were deemed to be promoted, or acquiesced to by developed nation. It is important to note that responses to items in the questionnaire were generally more subdued than in the focus group discussions. Additionally, claims by discussants that police raids on cyber cafes were often unjustified or linked to police corruption may also have some validity, as shown in complaints by a cyber café operators in Festac Lagos (Nairaland, 2005).

There are clear relationships between internet scamming and the theoretical views expressed here. First, in line with Cohen (1955) views a fast growing practice of 419 internets scamming by undergraduates represents the growth of a subculture that is at variance with mainstream culture, though these youth are not necessarily from the lower working class. Also, it is evident that responsibility for undergraduate 419 scamming rests largely on the pressures exerted upon youth by factors located in Nigerian society. Secondly, there is an element of labelling theory by which youth criminality is highlighted, while a general environment of corruption continues to fester. Sometimes, as observed by discussants, when the police raid cyber cafes in search of 419 scammers, they themselves use such opportunities to perpetuate corruption. Labelling of youth by the police is already a major problem in Nigeria and has sometimes resulted in unwarranted physical attacks on youths as individuals or groups, leading to loss of lives. Thirdly, persistent use of computers and internet for the 419 scam clearly constitutes an example of Fiske's postulation (1989) that consumers' in capitalist societies sometimes make use of products in ways not originally intended by producers. 


\section{Recommendations}

Discussants' responses often gave clear indications as to the areas in which government was required to effect changes towards eradication of advance fee fraud. Curbing the whole gamut of corruption related offences in Nigeria is one area that is long overdue. In this regard, the effectiveness of law enforcement mechanisms, and the judiciary need to be improved. Though much hope has been expressed for the success of the Economic and Financial Crimes Commission (EFCC), (Logan, 2006), with regard to internet scam, this hope is yet to fully materialize according to Nairaland (2009); as EFCC has only recently initiated a major plan to crackdown on the high incidence of 'fraudulent mails'. Based on the findings of this study the following recommendations are therefore posited.

- Adequate use of the judicial system, together with committed effort on the part of the law enforcement agents, and the alertness of the general public are of vital importance for success in curbing all the dimensions of this crime.

- There is a need not only to enact laws in Nigeria and other concerned countries, that will criminalize scammers as well as 'victims', but to actually effectively apply such laws. Letters written by scammers to bait victims usually contain element of illegality, and so those who become victims, often themselves actually set out to defraud governments, state authorities or other legitimate groups or individuals in one way or another.

- There is a strong need to re-examine a potentially useful corruption curbing institution such as the EFCC with a view to providing it with increased capability to effectively carry out its functions.

- Generating required opportunities for large scale gainful employment for youth is vital to success in dealing with this social problem. Presently, rather than a comprehensive approach to expanding employment, government has left this to the private sector, that is already constrained by lack of necessary infrastructure and logistics as well as inadequacy of vital government policies.

- Sustained collaboration with international cyber crime detecting and investigative agencies and improved use of sophisticated technology is vital to success in drastic reduction of 419 internet fraud. Activities in this direction were already underway by 2005, according to McCue (2005).

- It is also essential that the populace at large be made aware of the negative impact of the 419 scam on Nigeria's international image through sustained public enlightenment.

- Sustained publicity focused on the roots of advance fee fraud would also facilitate review of past and present failures on the road to socio-economic and political modernization and development, with a view to making necessary amendments and adjustments. Above publicity would in turn help to instil into public consciousness the need for integrity, responsibility, and accountability at all levels of society. 


\section{Conclusion}

Scammers are quite often very intelligent undergraduates or young graduates. Firstly, they are adept at gauging the directions of interests of their victims. Secondly, more recently they have also shown that they can formulate interesting, credible, ostensibly fraud-free business proposals to attract upright entrepreneurs (Bloch, 2007; Vaknin, 2005). Thirdly, in the process of scamming, these youth also become proficient at impersonation, cracking of bank security procedures, e-mail boxes and so on. Legitimate employment of such youth would serve to advance the stock of Nigeria's information technology skills. Furthermore, it would serve the purpose of discouraging ongoing formation and consolidation of an undergraduate sub-culture of internet and other forms of fraud.

\section{References}

Adebayo, B. 2001. “\$23 billion “419” Swindle Lagos.” The News October 9. Http://www.freemaninstitute.com/419news.htm. (Retrieved 20 Sept 2008).

Anderson, N. 2006. "Nigerian 419 Scams: Effective as Ever". July 20. Http://arstechnica.com/old/content/2006/07/7307 (Retrieved 15 Aug 2009).

Apter, A. 1999. 'IBB-419: Nigerian Democracy and the Politics of Illusion' in J. Comaroff and J. Comaroff (eds.). Civil Society and the Political Imagination in Africa. Chicago: University of Chicago Press.

Asiama-Sampong 2005. "Country Report Ghana": Resource Material Series No. 67. (Retrieved 10th July 2007).

Barlow, J. G. 2001. "Net War" Http:/beis.pacificu.edu/journal/2001/10/ editorial/10:php. (Retrieved 15th August 2007).

Bloch, M. 2007."Nigerian Scams Affecting E-commerce Merchants". Http://www.tamingthebeast.net/articles5/nigerian-scams-ecommerce.htm. (Retrieved 21 October 2009).

Chambliss, W. J. 1978. 'The Saints and the Roughnecks' Society: Nov. 6th.

Cohen, A. 1955. Delinquent Boys. London: Free Press.

Egbue, N. G. 2008. 'Elite Values and Socio-Political Underdevelopment of Africa: The Case of Nigeria'. In Onwuka (ed.). The Third World in Social Science Perspective. Owerri: Ferp-Fasmen.

Fanon, F. 1983. The Wretched of The Earth. Harmondsworth: Penguin books. Fiske, J. 1989. Understanding Popular Culture. London: Unwing Hyman.

Freeman Institute 2005. "GSM Fraudsters After Anyaoku Arrested". Http://www.freemaninstitute.com/419news.htm. (Retrieved 8 Oct. 2008).

Gaye, D. C. 1999. Ethnic clashes in Nigeria A Nightmare vision of what capitalism has to offer Lagos, ICC articles, Nigeria, December. Http://www.worldarchitecture.org/cities-uia-2005/index.asp?rec=225. (Retrieved 10 Feb. 2008).

Gbadebo, M. 2009. "Fraud is a Global Problem". January. Http:// www. nigeriafraud.org/. (Retrieved August 12 2009). 
Golding, P. and Murdock, G. 1991. 'Cultural Communication and Political Economy' in I. Curran and M. Gurevitch (eds.) The Mass Media and Society. London: Edward Armold.

Hanker, H. 2006. 'Sociology of Corruption and the Corruption of Sociology' Current Sociology Vol. 54, No. 1, Pg. 25-38.

Hannaford, C. 2007. All About Cookie Jars-Financial Statement Fraud. Paper Presented at Niagara College. Ontario (Feb 28, 2007). Retrieved 28 Aug 2007.

Igbo, E. U. B. 1999. Introduction to Criminology. Nsukka: Afro-Orbis Publ.

Logan, T.2006. Http://news.bbc.co.uk/2/hitechnology/3526209.stm (Retrieved 3 September 2007).

Mbachu, D. 2005. "Yahoo-Yahoo" Nigerian Internet Scam Spam: Don't be a Victim". August 27. Http://nigeriantimes-blogspot.com/2005/08/yahooyahoo-nigerian-internet-scam.html. Retrieved 7 December 2008).

McCue, A. 2005. "Nigeria Enlists Microsoft to Fight 419 Scammers". 14 October. Http://www.silicon.com/technology/security/2005/10/14/nigeriaenlists-microsoft-to-fight.

McGew. 1992. 'A Global Society'? In Halls et al. Modernity and its Pictures. Polity Press.

Nairaland Forum. 2009. "Nigeria in Big Scamster Crackdown". 23 October. Http://nairaland.net//forum/viewtopic.php?p=3669\&sid=05ccc6841b44e05 64f6db86f89691.

Nairaland Forum. 2005. "Cyber Café in Festac Having Problems with the Police 419". Http://www.nairaland.com/nigeria/topic-2522.0.html (Retrieved 4th March 2009).

National Planning Commission. 2004. 'Nigeria: National Economic Empowerment and Development Strategy' (NEEDS). Abuja: NPC.

Pearce, F. 1976. Crimes of the Powerful, London, Pluto Press.

Peel, M. 2006. "Nigeria Scams Cost UK Billions". 20 November. Http://news.bbc.co.uk/i/hi/business/6163700.stm (Retrieved 5 Sept 2007).

Reich, P. 2004. Cyber Crime: Advance Fee Scams in Country and Across (PDF).

Rodney, W. 1982. How Europe Underdeveloped Africa. Enugu: Ikenga Publishers.

Seabrook, J. 1998. Victims of Development: Resistance and Alternatives. London: Verson.

Smith et al. 1999. Nigeria Advance Fee Fraud Study (PDF).

Sofo, C. A.; Ali-Akpajiaka and Pyke, T. 2003. Measuring Poverty in Nigeria, Oxford: Oxfarm.

Spitzer, S. 1980. 'Toward A Marxian Theory of Deviance' in D.H. Kelly (eds.). Criminal Behaviour, Reading in Criminology. New York: St. Martins Press.

Taylor, Walter and Young. 1973. The New Criminology: For a Social Theory of Deviance, London: Routledge and Kegan Paul. 
The African Development Bank Group (2003) African Development Report (2003) Oxford: Oxford University Press.

Trevelyan, M. 2009. "Nigerian Student Gets 19 Years Jail for Love Scam". March 16. Http://uk.reuters.com/article/idUKTRE52F5C820090316. (Retrieved 14 October 2009).

United Nations Office of Drug and Crime. 2005. Transnational Organized Crime in West Africa Region. Vienna: United Nations.

Vaknin, S. 2005. "Nigerian Scam-Begging your Trust in Africa". May. Http://samvak.tripod.comlnigeriascam.html (Retrieved 18 August 2008).

World Bank. 1996. Taking Action to Reduce Poverty in Sub-Saharan African: Overview. Washington D.C.: The International Bank for Reconstruction and Development. 